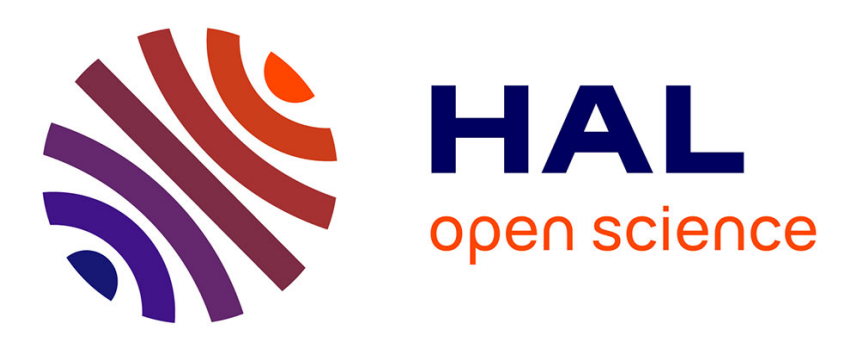

\title{
A validation study on status and age of natural menopause reported in the E3N cohort.
}

Françoise Clavel-Chapelon, N. Dormoy-Mortier

\section{To cite this version:}

Françoise Clavel-Chapelon, N. Dormoy-Mortier. A validation study on status and age of natural menopause reported in the E3N cohort.. Maturitas, 1998, 29 (2), pp.99-103. inserm-00175348

\section{HAL Id: inserm-00175348 https://www.hal.inserm.fr/inserm-00175348}

Submitted on 27 Sep 2007

HAL is a multi-disciplinary open access archive for the deposit and dissemination of scientific research documents, whether they are published or not. The documents may come from teaching and research institutions in France or abroad, or from public or private research centers.
L'archive ouverte pluridisciplinaire HAL, est destinée au dépôt et à la diffusion de documents scientifiques de niveau recherche, publiés ou non, émanant des établissements d'enseignement et de recherche français ou étrangers, des laboratoires publics ou privés. 


\title{
A validation study on status and age of natural menopause reported in the E3N cohort
}

\author{
F. Clavel-Chapelon ${ }^{*}$ and N. Dormoy-Mortier \\ Institut National de la Santé et de la Recherche Médicale (U351), Institut Gustave-Roussy, 94805 Villejuif, France
}

\begin{abstract}
The accuracy of self-reported menopausal status and age at menopause has been analysed in a validation study using the gynecologist's medical records as the reference. Concordance between the two sources for menopausal status was assessed in 151 women. The kappa coefficient obtained was 0.85 (95\% CI, 0.691.00). Agreement on age at menopause was tested in 57 women and the kappa coefficient obtained was 0.64 (95\% CI, 0.34-0.94). Age at menopause was accurately reported by $32 \%$ of the subjects. This percentage increased to 69 and $86 \%$ when agreement within 1 and 2 year(s) was considered, respectively. These results suggest that women can provide data on their natural menopause history with sufficient accuracy to test some hypotheses associating this event with the evolution of their health status.
\end{abstract}

Author Keywords: Self-reported menopausal status; Age at menopause; Medical records; Health status

\section{Introduction}

Epidemiological studies commonly use self-administered questionnaires as a source of information on exposure. Recently there has been a growing interest in the epidemiological literature on the reliability of data recorded therein. Validation studies help to determine the extent of the agreement between selfreported data and an external source, considered as the reference.

Age at menopause is of particular concern in major diseases [1], such as breast cancer or osteoporosis, and the need to examine the accuracy of self-reports on age at menopause has been underlined by several authors $[2,3]$. We examined the validity of the menopausal status and of age at menopause self-reported by women in the E3N study, a prospective study on the relationship between lifestyle and diet, and the occurrence of cancer and other major illnesses in women [4]. As information on artificial menopause is easier to recall or collect from medical records, our main concern was the accuracy of natural menopause and age at natural menopause.

\section{Material and methods}

The cohort comprises approximately 100000 women, aged 40-65 years in 1990, members of the MGEN, a French health insurance plan. In 1990, participants were asked to complete a self-administered questionnaire, which recorded information on their menopausal status (were they pre- or postmenopausal?), with a third option proposed when the menopause was not settled. Age at menopause was also - eventually - recorded. Table 1 describes the menopausal status of $94850 \mathrm{E} 3 \mathrm{~N}$ participants at entry in the study. Half of them were premenopausal, $35.0 \%$ reported that they were post-menopausal, naturally in $24.4 \%$ or artificially in $9.8 \%$ (with a mean age at menopause of $50.2(\mathrm{SD}=4.2)$ and $44.2(\mathrm{SD}=6.2)$ years, respectively) and $12.6 \%$ reported irregular menses.

After exclusion of participants who did not answer the question on menopausal status, we selected at random a sample of the first 171 questionnaires of women who had a gynecologist's medical record at the MGEN clinic in Paris, and who had given us permission to contact him/her. Of this total validation group, 20 women were excluded because of artificial menopause. The present analysis thus concerns 151 women. Agreement between the answer given in the self-administered questionnaire and the information collected from the medical record was tested for the menopausal status. Kappa coefficients, defined as the ratio of the actual agreement beyond chance over the potential agreement beyond chance, were calculated [5].

The reference chosen was the gynecologist's medical records that were kept in the MGEN clinic. The concordance was established on the menopausal status between the answer of the woman on the questionnaire and the answer of the physician at the visit following the filling in of the questionnaire. For

\footnotetext{
${ }^{*}$ Corresponding author : clavel@igr.fr
} 
women considered postmenopausal from both sources, the concordance on the dates of the menopause was also studied. The date of examination, from which age at menopause was ascertained, was the date at which the physician had notified his/her menopause in the medical record (we chose the date closest to the menopause).

Table 1. Description of the self-reported answers to the menopausal status of 94850 E3N participants ${ }^{\mathrm{a}}$

\begin{tabular}{lrr}
\hline Characteristic & n & \% \\
\hline Menopausal status & & \\
premenopausal & 47730 & 50.3 \\
postmenopausal & 33100 & 35.0 \\
natural $_{\text {artificial }^{\mathrm{b}}}$ & 23122 & 24.4 \\
incoherent+missing $_{\text {unsettled menopause }}$ & 9258 & 9.8 \\
missing & 720 & 0.8 \\
\hline
\end{tabular}

${ }^{a}$ those having complete inclusion criteria data (i.e with informed consent signed, and check of the data performed)

${ }^{b}$ includes women with a history of hysterectomy without ovariectomy

\section{Results}

The menopausal status from both sources is shown in Table 2. Women who replied that their menopause was unsettled were classified as 'pre-menopausal women'.

Table 2. Agreement on the menopausal status as self-reported or indicated in the medical record (number of women in parentheses)

\begin{tabular}{|c|c|c|c|}
\hline & \multicolumn{2}{|c|}{ From the medical record as: } & \multirow{2}{*}{ Total } \\
\hline & pre-menopausal & post-menopausal & \\
\hline \multicolumn{4}{|l|}{ Self-reported as: } \\
\hline premenopausal & $54 \%(81)$ & $5 \%(8)$ & $62 \%(89)$ \\
\hline postmenopausal & $2 \%(3)$ & $39 \%(59)$ & $38 \%(62)$ \\
\hline Total & $57 \%(84)$ & $43 \%(67)$ & $(151)$ \\
\hline
\end{tabular}

In the medical record, $43 \%$ were post-menopausal women. According to self-reports, $38 \%$ of women were post-menopausal. Three of the 84 women registered as pre-menopausal in the medical record indicated that they were menopausal in the questionnaire. Among the 67 women registered as menopausal by the gynecologist, eight replied in the questionnaire that they were pre-menopausal. The corresponding kappa coefficient was 0.85 (95\% CI, 0.69-1.00).

Two out of the 59 menopausal women according to both sources did not provide their age at menopause. Agreement between the self-administered questionnaire and the reference on age at menopause was thus tested in 57 women. Age at menopause was accurately reported by $32 \%$ of the women (Table 3 ). This percentage increased to 69 and $86 \%$ when agreement within 1 and 2 year(s) was considered, respectively. Age reported was younger than the reference age for $43 \%$ and older for $25 \%$. A weighed kappa coefficient was calculated. A weight of 1 was allocated to answers with agreement of within 1 year. For agreement within 2 years, a weight of 0.5 was given. Women with a difference between self-reporting and the reference exceeding 2 years were assigned a weight of 0 . The resulting kappa coefficient was 0.64 (95\% CI, 0.34-0.94).

\section{Discussion}

Our study showed that self-reporting of menopausal status and of age at menopause is in good agreement with the gynecologist's medical record.

Few studies have assessed the validity of such information when obtained from subjects enrolled in epidemiological studies, even though it is most important in the occurrence of major events, such as breast cancer or osteoporosis. Bean et al. [6] analysed the data from the Menstrual and Reproductive History study, a study on women whose menstrual status had been recorded from when they were at university until natural menopause over a period extending from 1934 to 1974. Bean et al. examined the accuracy of recall to questions concerning age at menopause, by comparing the original data recorded as events occurred to 
answers to a questionnaire administered in 1979. Among the 49 subjects who had reached a natural menopause by $1974,45 \%$ correctly recalled their age when it occurred. Agreement within 1 year was observed for $75 \%$ and within 2 years for $86 \%$. The corresponding percentages observed in our study $(31,70$ and $86 \%$, respectively) are quite similar. However, their study differs from ours in that the authors compared the age at which an event occurred, as reported by the same person, at two dates.

Table 3. Accuracy of recalled age at menopause

\begin{tabular}{ccc}
\hline Difference $^{\mathbf{a}}$ in years & No. $(\boldsymbol{n}=\mathbf{5 7})$ & \% \\
\hline-6 & 1 & 2 \\
-5 & 2 & 3 \\
-4 & 1 & 2 \\
-3 & 2 & 3 \\
-2 & 6 & 10 \\
-1 & 13 & 23 \\
0 & 18 & 32 \\
+1 & 8 & 14 \\
+2 & 4 & 7 \\
+3 & 1 & 2 \\
+4 & 1 & 2 \\
\hline
\end{tabular}

In another study on 67 women, Paganini-Hill et al. [7] compared the accuracy of age at natural menopause evaluated during an interview to the age obtained from the medical record in four age groups $(\leq 44,45-49$, $50-54$ and 55 or over). Forty-eight percent of the women correctly ranked it in the same 5-year age group. In our study, $74 \%$ did so. Earlier studies cited by Brambilla and McKinlay [8] reported marked terminal digit clustering of reported age at natural menopause which was not observed in our sample. In our study, we observed a single mode, equal to 51 years of age for the self report and to 52 for the external report.

Brambilla and McKinlay also pointed out that education or socioeconomic status is a good predictor of the accuracy of self-reports. These factors could partly explain our results, since $82 \%$ of the women in our cohort had been to secondary school, whereas this corresponds to $21 \%$ of women of a similar age in the general French population [9].

As menstrual cycles are frequently irregular during the period preceding their definitive cessation, it is difficult to specify the date of the natural menopause which can only be determined retrospectively when menstruation has failed to occur over a 12-month period $[10,11]$. It can be assumed that this was the definition adopted by doctors in the medical record, since it is the definition taught and commonly used in France [10]. For the self-report, menopause was not defined in the questionnaire. Our study was thus comparable to realistic situations.

Women whose status was uncertain and who replied that they had an unsettled menopause were classified as premenopausal. Excluding them from the analysis would enhance the kappa coefficients for the menopausal status to $0.95(P<0.0001)$.

The definition of the date of the natural menopause for women on hormonal treatment is of particular concern, especially when women constantly used oral contraceptives before hormonal replacement therapy. Such women were not excluded from our analysis as hormonal treatments consumed throughout life were not recorded at entry in the study. Whether such women may have distorted our results is, however, uncertain.

The representativeness of the sample used in this study was ascertained by comparison with the population of the whole cohort in terms of age-adjusted menopausal status (premenopausal, artificial or natural menopause) and age at menopause.

Concerning age at menopause, the choice of the reference can be discussed. The reliability of the medical record is highly dependent on the interval between the event (menopause) and the medical examination. As clinical examinations are free of charge for members of the MGEN, this interval proved to be particularly short (mean=10.3 months; $\mathrm{SD}=12$ ).

Finally, the information collected in the questionnaire and in the medical record may have influenced each other if the date of the examination from which age at menopause was ascertained, and the date on which the questionnaire was filled in were close. Indeed, the interval between these dates seemed long enough to reduce this potential bias. Its median duration was equal to 31 months and the highest quartile to 77 months. 
Moreover, the within-1 year agreement on age at menopause reported by the woman or the physician did not significantly differ by time elapsed since the menopause: it was equal to $80 \%$ (95\% CI, 55-100), $67 \%$ $(95 \% \mathrm{CI}, 36-98)$ and $68 \%(95 \% \mathrm{CI}, 55-81)$ for categories of duration of $\leq 24,24-59$ and 60 months or more, respectively.

Our study provides information on a topic studied by few authors. Due to the level of education of our population, our results may be considered optimal. However, our investigation offers the opportunity to assess the reliability of self-reported data on age at menopause after a rather long period, as 6.0 years $(\mathrm{SD}=4.8)$ on average had elapsed between the date of their menopause and the date of the questionnaire. Our results suggest that women can provide data on their natural menopause history with sufficient accuracy to study that event which is of special interest towards major health disorders such as cancers or cardiovascular diseases.

\section{Acknowledgements}

We would like to thank L. Saint-Ange for the linguistic revision of the manuscript, V. Avenel and S. Goldstein for their assistance and M. Lê for her helpful comments. The E3N cohort study is being carried out with the financial support of the 'Europe against Cancer' Programme of the European Union, the 'French League Against Cancer', the '3M Company', the 'Mutuelle Générale de l'Education Nationale' and the 'Institut National de la Santé et de la Recherche Médicale'.

\section{References}

1. M.R. Sowers and M.T. LaPietra, Menopause: its epidemiology and potential association with chronic diseases. Epidemiol Rev 17 (1995), pp. 287-302.

2. M. Goodman, Toward a biology of menopause. Signs 5 (1980), pp. 739-753.

3. P. Kaufert, M. Lock, S. McKinlay, Y. Beyenne, J. Coope, D. Davis, Eliasson, M. Gognalons-Nicolet, M. Goodman and A. Holte, Menopause research: The Korpilampi workshop. Soc Sci Med 22 (1986), pp. 1285-1289.

4. Clavel-Chapelon F, the E3N Group. E3N, a French cohort study on cancer risk factors. Eur J Cancer Prev 1997;6:473-8

5. Fleiss JL editor. The measurement of interrater agreement. In: Statistical Methods for Rates and Proportions. New York, NY: Wiley, 1982.

6. J.A. Bean, J.D. Leeper, R.B. Wallace, B.M. Sherman and H. Jagger, Variations in the reporting of menstrual histories. Am J Epidemiol 109 (1979), pp. 181-185.

7. A. Paganini-Hill, M.D. Krailo and M.C. Pike, Age at natural menopause and breast cancer risk: the effect of errors in recall. Am J Epidemiol 119 (1984), pp. 81-85.

8. D.J. Brambilla and S.M. McKinlay, A prospective study of factors affecting age at menopause. J Clin Epidemiol 42 (1989), pp. 1031-1039.

9. Institut National de la Statistique et des Etudes Economiques (INSEE). Census of the French population, 1982.

10. Drapier-Faure E. Ménopause et son traitement. Paris, France: Editions Techniques, Encycl Méd Chir (Gynécologie), 1992.

11. K.T. Khaw, Epidemiology of the menopause. Br Med Bull 48 (1992), pp. 249-261. 